\title{
Metastatic Malignant Neoplasm in the
} Chest Wall

National Cancer Institute

\section{Source}

National Cancer Institute. Metastatic Malignant Neoplasm in the Chest Wall. NCI

Thesaurus. Code C8530.

A malignant neoplasm that has spread to the structures of the chest wall from another primary anatomic site. 